\title{
Kemampuan Koneksi Matematis Siswa pada Pembelajaran Matematika Berbasis Patchwork Assessment
}

\author{
Buyung \\ STKIP Singkawang, Singkawang, Indonesia \\ 21.buyung@gmail.com \\ ${ }^{*}$ Corresponding author
}

\author{
Kata Kunci: \\ Patchwork Assessment; \\ Kemampuan Koneksi \\ Matematis; Pembelajaran \\ Matematika
}

\begin{abstract}
ABSTRAK
Kemampuan koneksi matematis siswa masih kurang, kemampuan koneksi matematis siswa masih belum maksimal, seperti siswa kurang paham pada materi pelajaran sehingga tidak berani menyampaiakan materi saat melakukan diskusi. Penelitian ini bertujuan untuk mengetahui kemampuan koneksi matematis siswa pada pembelajaran matematika berbasis Patchwork Assessment. Penelitian ini merupakan penelitian eksperimen semu (quasi experimental). Sumber data dalam penelitian ini adalah hasil tes kemampuan koneksi matematis. Pembelajaran matematika berbasis Patchwork Assessment. Teknik pengumpulan data yang digunakan dalam penelitian ini dokumentasi dan tes. Uji prasyarat ini meliputi uji normalitas, uji homogenitas, sedangkan uji hipotesis menggunakan uji perbedaan rata-rata. Hasil penelitian berdasarkan hasil output SPSS diperoleh nilai signifikan = 0.012 , karena nilai signifikan $0.012<0.05$, maka diperoleh bahwa rata-rata kemampuan koneksi matematis siswa pada kelas dengan pembelajaran matematika berbasis patchwork assessment lebih baik daripada kemampuan koneksi matematis siswa pada kelas kontrol.
\end{abstract}

\section{PENDAHULUAN}

Indonesia menunjukkan keidentikan pada hasil belajar matematika yang selalu mendapatkankan hasil yang tidak maksimal, Ketakutan banyak pelajar di Tanah Air kepada mata pelajaran itu terlihat dari hasil Survei Programme for International Student Assessment (PISA). Studi PISA yang mengukur kemampuan anak usia 15 tahun dalam literasi membaca, matematika, dan ilmu pengetahuan, pada tahun 2015, menempatkan Indonesia pada peringkat 63 dari 69 negara peserta survei (OECD, 2015). Sedangkan pada TIMSS (Trend in Mathematics and Study Science) yang diikuti di tahun 2015, Indonesia menduduki peringkat 45 dari 49 peserta dengan skor 397 (TIMSS, 2015).

Hasil observasi yang dilakukan di SMP Torsina I Singkawang dengan memberikan soal yang mengandung indikator koneksi pada materi barisan dan deret. Peneliti mengajukan sebuah soal dengan dua indikator koneksi matematis kepada 35 orang siswa. Hasil yang didapatkan dari observasi tersebut menunjukkan bahwa kemampuan koneksi matematis siswa cukup rendah untuk kedua indikator koneksi yang disajikan. Kemampuan koneksi matematis siswa masih belum maksimal, seperti siswa kurang paham pada materi pelajaran sehingga tidak berani menyampaiakan materi saat melakukan 
diskusi. Bruner (Ruspiani, 2000: 19) menyatakan bahwa dalam matematika setiap konsep itu berkaitan satu sama lain seperti dalil, antara teori dan teori, antara topik dengan topik, antar cabang matematika.

Merujuk hasil observasi penelitian ini menunjukkan kemampuan koneksi matematis siswa masih kurang ditunjukkan dengan sebagian besar siswa belum bisa menggunakan konsep deret geometri tak hingga. Hasil penelitian The National Assesment of Educational Progress (NAEP) memperkuat pendapat bahwa siswa memperoleh prestasi baik hanya pada konteks yang dikenal siswa, tetapi tidak untuk konteks yang tidak dikenal mereka meskipun untuk permasalahan matematika yang sama (Kouba et al., 1988). Masalah utama yang perlu ditangani secara garis besar adalah kemampuan koneksi matematis. Kemampuan koneksi matematis siswa yang merupakan kemampuan siswa dalam mengkoneksikan ide satu dengan ide lain sehingga dalam menghasilkan suatu keterkaitan yang menyeluruh masih kurang dan mengoneksikan antar ide matematis pula siswa masih kurang.

Bertolak pada hasil di atas, peneliti menyimpulkan perlunya ditingkatkan kemampuan koneksi matematis siswa pada sekolah tersebut. Indikasi siswa yang menunjukkan kemampuan koneksi matematis yakni ketika mereka dapat memenuhi indikator koneksi matematis yang sesuai dengan apa yang dikemukakan oleh National Council of Teaching Mathematics (2000) antara lain: (1) Mencari hubungan berbagai representasi konsep dan prosedur; (2) Memahami hubungan antar topik matematis; (3) Menerapkan matematika dalam bidang lain atau dalam kehidupan sehari-hari; (4) Memahami representasi ekuivalen sebuah konsep; (5) Mencari hubungan suatu prosedur dengan prosedur lain dalam representasi yang ekuivalen; (6) Menerapkan hubungan antar topik matematis dan antara topik matematis dengan topik di luar matematika.

Untuk mencapai kemampuan koneksi siswa dalam matematika bukanlah suatu hal yang mudah karena kemampuan untuk mengkoneksikan dalam matematika dilakukan secara individual. Setiap peserta didik mempunyai kemampuan yang berbeda dalam mengkoneksikan hubungan dalam matematika. Hal ini menjadi tantangan tersendiri untuk menetapkan strategi yang tepat untuk meningkatkan unsur High Order Thingking Skill tersebut.

Strategi pembelajaran telah banyak dikembangkan oleh beberapa ahli pendidikan. Salah satunya mengenai teori belajar bermakna oleh David Ausubel. Ausubel (Joyce, 2009: 280) mengemukakan teorinya bahwa pembelajaran bermakna berhubungan dengan tiga hal, yaitu: (1) bagaimana pengetahuan (materi kurikulum) dikelola; (2) bagaimana pikiran bekerja dalam memproses informasi baru (pembelajaran); dan (3) bagaimana guru mengaplikasikan gagasan-gagasan ini pada kurikulum dan pembelajaran ketika mereka mempresentasikan materi baru pada siswa. Berdasarkan teori tersebut, Ausubel menganjurkan peningkatan metode-metode pengajaran presentasional (Joyce, 2009: 280). Pengajaran presentasional yang dimaksud salah satunya adalah advance organizer. Model pembelajaran advance organizer ini dirancang untuk memperkuat struktur kognitif siswa mengenai pengetahuan mereka tentang pelajaran tertentu dan bagaimana mengelola, memperjelas, dan memelihara pengetahuan tersebut dengan baik (Ausubel dalam Joyce, 2009: 281). Dengan kata lain, sebelum mempelajari suatu konsep, siswa telah disiapkan untuk dapat membangun struktur kognitif. Kemudian setelah konsep diberikan, siswa dapat mengelola, memperjelas dan memelihara konsep tersebut dengan baik. Jika dilihat teori belajar tersebut sangat cocok seperti tugas yang diberikan agar siswa bisa membangun pengetahuan, pikiran dan mengaplikasikan gagasannya.

Alternatif solusi lain agar siswa lebih aktif dalam memahami konsep- konsep matematika dan mengaitkan satu konsep dengan konsep yang lain adalah patchwork assessment. Penilaian patchwork assessment memanfaatkan pada belajar menjadi proses bertahap dan difasilitasi oleh proses berkelanjutan umpan balik dan evaluasi (Brunsden, (2007a).

Perancangan tugas pada patchwork assessment ini, guru lebih mampu memecahkan masalah matematika dari tingkatan yang rumit menjadi lebih kecil serta lebih teratur dimana memungkinkan siswa menentukan keterkaitan antara satu konsep dengan konsep lainnya dengan jelas. Siswa dapat pula mengukur kemampuan mereka sendiri serta menuntut mereka untuk mencari bantuan dari teman 
sekelas atau guru. Di lain sisi, pada proses pembelajaran terjadi keterlibatan siswa dan tanggung jawab menyelesaikan tugas. Serangkaian tugas diatur sedemikian rupa sehingga dimana di mana tugas awal mempersiapkan siswa untuk tugas akhir, serta untuk materi pembelajaran lain yang terkait. Menurut salah satu pioneer yang mencetuskan proses patchwork assessment, Winter, Parker, and Ovens (2003: 112) mengemukakan bahwa: "The essence of a patchwork is that it consists of a variety of small sections, each of which is complete in itself, and that the overall unity of these component sections, although planned in advance, is finalized retrospectively, when they are 'stitched together".

Menurut Brown et al. (1996, 142-3), patchwork assessment memiliki beberapa prinsip yakni: (a) Penilaian harus didasarkan pada pemahaman tentang bagaimana siswa belajar. (b) Penilaian harus mengakomodasi perbedaan individual siswa. (c) Bentuk penilaian harus memungkinkan siswa untuk menerima umpan balik pada pembelajaran mereka. (d) Penilaian harus menyediakan staf dan siswa dengan kesempatan untuk merefleksikan praktek mereka dan belajar mereka. Penilaian harus menjadi komponen integral dari desain pembelajaran dan bukan sesuatu yang terlepas pada kegiatan sesudahnya. Seperti yang diuraikan oleh Ovens (2003), pelaksanaan penilaian patchwork assessment sangat bervariasi dalam hal praktek pemilihannya.

\section{METODE PENELITIAN}

Metode penelitian yang digunakan pada penelitian ini adalah metode penelitian kuantitatif. Penelitian ini merupakan penelitian eksperimen semu (quasi experimental). Tahapan kuantitatif yang dilaksanakan mencakup beberapa hal, yaitu: memberikan tes koneksi matematis awal, melaksanakan proses pembelajaran dengan patchwork assessment dan memberikan tes koneksi matematis akhir. Instrumen tes kemampuan koneksi matematis yang digunakan meliputi uji validitas, uji reliabilitas, uji daya beda, dan uji taraf kesukaran.

Populasi dalam penelitian ini adalah siswa kelas VIII SMP Torsina I Singkawang. Penentuan sampel dalam penelitian ini menggunakan teknik cluster random sampling. Cara pengambilan sampel menurut Sugiyono (2010) dapat dilakukan apabila anggota populasi dianggap homogen. Dalam tahapan kuantitatif, terdapat dua kelas sampel yang dipilih yang merupakan hasil pemilihan secara acak dari kelas-kelas reguler yang homogen. Dua sampel tersebut diacak kembali sehingga diperoleh satu kelas sebagai kelas kontrol dan satu kelas sebagai kelas eksperimen.

Sumber data dalam penelitian ini adalah hasil tes kemampuan koneksi matematis. pembelajaran matematika berbasis patchwork assessment. Teknik pengumpulan data yang digunakan dalam penelitian ini dokumentasi dan tes. Metode dokumentasi ini digunakan untuk mendapatkan data-data yang mendukung penelitian yaitu nama peserta didik yang menjadi sampel dalam penelitian dan nilai tes kemampuan awal yang digunakan untuk penentuan sampel. Teknik tes pada penelitian ini digunakan untuk mengukur tes kemampuan koneksi matematis. Tes kemampuan koneksi matematis diberikan kepada subjek penelitian dalam bentuk soal tes tertulis dan berbentuk uraian.

Analisis data kuantitatif terbagi menjadi tiga bagian yaitu analisis uji prasyarat, analisis efektifitas pembelajaran dan analisis uji hipotesis. Analisis uji prasyarat merupakan pengujian awal untuk memastikan data dapat digunakan sebelum dilaksanakan pembelajaran berbasis patchwork assessment. Uji prasyarat ini meliputi uji normalitas, uji homogenitas, sedangkan uji hipotesis menggunakan uji perbedaan rata-rata.

\section{HASIL DAN PEMBAHASAN}

Hasil penelitian data kuantitatif kemampuan koneksi matematika diperoleh dari hasil tes yang diberikan pada siswa. Statistik deskriptif data akhir rata-rata kamampuan koneksi matematis siswa kelompok eksperimen dan kelompok kontrol pada disajikan pada Tabel 1. 
Tabel 1. Rata-Rata Kelas Eksperimen dan Kelas Kontrol

\begin{tabular}{lllll}
\hline & Kelas & $\boldsymbol{N}$ & Mean & Std. Deviation \\
\hline Nilai & 1 & 30 & 75,55 & 7,050 \\
& 2 & 29 & 70,55 & 6,566 \\
\hline
\end{tabular}

Uji normalitas dilakukan dengan bantuan SPSS, kriteria pengambilan keputusan adalah terima H0 jika nilai Sig. $>5 \%$. Berikut hasil uji normalitas data akhir kemampuan koneksi matematis siswa dengan uji Kolmogorov-smirnov. Berdasarkan hasil analisis uji normalitas data akhir, diperoleh nilai signifikan $=0,522=52,2 \%>5 \%$. Jadi $\mathrm{H}_{0}$ diterima, artinya data berasal dari populasi yang berdistribusi normal.

Kriteria pengambilan keputusan adalah terima H0 jika nilai Sig. $>5 \%$. Berdasarkan hasil output SPSS diperoleh nilai signifikan $=0,646$, karena nilai signifikan 64,6\% >5\%, maka $\mathrm{H}_{0}$ diterima. Kesimpulan yang diperoleh bahwa varians kelas eksperimen sama dengan varians kelas kontrol.

Uji perbedaan rata-rata kemampuan koneksi matematis digunakan untuk mengetahui perbedaan ratarata antara nilai tes kemampuan koneksi matematis kelompok kelas eksperimen dan nilai tes kemampuan koneksi matematis kelas kontrol. Berdasarkan hasil perhitungan diperoleh nilai rata-rata siswa pada kelas pembelajaran matematika berbasis patchwork assessment adalah 75,55 dan nilai ratarata siswa pada kelas dengan pembelajaran ekspositori adalah 70,55 (Tabel 2).

Tabel 2. Perbedaan Kelas Eksperimen dan Kontrol

\begin{tabular}{lllll}
\hline & Eksperimen & Kontrol & $\boldsymbol{S}^{2}$ & $\boldsymbol{t}$ \\
\hline Rata-rata $x$ & 75,55 & 70,55 & & \\
Varians $S^{2}$ & 38,185 & 43,113 & 40,60 & 3,04 \\
Simpangan baku $(s)$ & 6,179 & 5,566 & & \\
$N$ & 30 & 29 & & \\
\hline
\end{tabular}

Hal ini berarti $\mathrm{H}_{0}$ ditolak, atau rataan kemampuan koneksi matematis siswa yang diajarkan dengan pembelajaran matematika berbasis patchwork assessment lebih baik daripada rataan kemampuan koneksi matematis siswa yang diajarkan dengan pembelajaran lain. Disimpulkan bahwa pembelajaran matematika berbasis patchwork assessment mampu memberi perubahan peningkatan kemampuan koneksi matematis siswa.

Kriteria pengujian $\mathrm{H}_{0}$ ditolak jika $t_{\text {hitung }}>t_{(1-\alpha)(\text { dff }}$, dimana $t_{(1-\alpha)(\text { df })}$ didapat dari daftar distribusi $t$ dengan $\mathrm{df}=\left(\mathrm{n}_{1}+\mathrm{n}_{2}-2\right)=57$ dengan peluang $(1-\alpha)=1-0,05=0,95$. Berdasarkan hasil perhitungan diperoleh $t_{\text {hitung }}=3,04>t_{(0,95)(57)}=1,6$ sehingga $\mathrm{H}_{0}$ ditolak bearti $\mathrm{H}_{1}$ diterima. Kriteria pengambilan keputusan dengan bantuan SPSS adalah terima H0 jika nilai Sig $>5 \%$.

Berdasarkan hasil output SPSS diperoleh nilai signifikan $=0,012$, karena nilai signifikan $0,012<0,05$. Kesimpulan yang diperoleh bahwa rata-rata kemampuan koneksi matematis siswa pada kelas dengan pembelajaran matematika berbasis patchwork assessment lebih baik daripada kemampuan koneksi matematis siswa pada kelas kontrol.

Berdasarkan uji perbedaan rata-rata kemampuan koneksi matematis kedua kelas yang diberikan perlakuan, yaitu kelas eksperimen dan kelas kontrol bahwa hasil menunjukkan bahwa kelas yang diberikan perlakuan pembelajaran matematika berbasis patchwork assessment lebih baik daripada kelas kontrol. Dari hasil posttest kemampuan rata-rata kelas eksperimen sebesar 75,55 sedangkan untuk kelas kontrol sebesar 70,55. Dengan demikian bahwa rata-rata kelas eksperimen lebih besar dari kelas kontrol.

Selisih perbedaan rata-rata kemampuan koneksi matematis antara siswa yang mengikuti pembelajaran matematika patchwork assessment pada kelas eksperimen dan yang mengikuti asesmen tradisional 
pada kelas kontrol lebih baik kelas eksperimen. Selisih tersebut menandakan kesenjangan yang terjadi antar asesmen, dimana nilai kemampuan koneksi matematis siswa yang mengikuti pembelajaran matematika berbasis patchwork assessment lebih tinggi dibandingkan siswa yang mengikuti asesmen tradisional. Berdasarkan pembelajaran matematika berbasis patchwork assessment yang melatih siswa terbiasa untuk memecahkan masalah dari yang sederhana sampai pada masalah yang lebih kompleks. Hal tersebut sejalan dengan pendapat Dewi \& Suweken (2014), dalam merancang tugas pada patchwork assessment ini, guru harus 'membongkar' masalah matematika yang kompleks ke dalam masalah yang lebih kecil dan lebih teratur sehingga siswa dapat melihat kaitan konsep-konsep tersebut dengan jelas, mengukur kemampuan mereka sendiri, dan mencari bantuan dari teman sekelas atau guru. Wesson (2013), interpretation and implementation of patchwork text assessment presented here are likely to be very different to those of others. Dalam waktu yang bersamaan, akan terjadi keterlibatan siswa dan tanggung jawab menyelesaikan tugas. Guru juga memberikan bimbingan untuk memastikan tugas yang dikerjakan siswa. Patchwork assessment disusun secara bertahap dan siswa dibimbing dalam melakukan serangkaian tugas penilaian singkat yang berkaitan dengan berbagai kegiatan yang telah ditentukan sebelumnya yang dirancang untuk mencakup hasil pembelajaran yang diinginkan (Leigh et al., 2013). Penilaian harus memberikan kesempatan kepada siswa agar lebih kritis merefleksikan penerapan hasil pekerjaan; meninjau dan belajar dari pengalaman belajar, pemecahan masalah dalam kehidupan nyata (Raelin, 2000).

\section{KESIMPULAN}

Berdasarkan hasil pengujian hipotesis dan pembahasan dalam penelitian ini, maka dapat disimpulkan bahwa terdapat perbedaan rata-rata kemampuan koneksi matematis kedua kelas yang diberikan perlakuan yaitu kelas eksperimen dan kelas kontrol yang menunjukkan bahwa kelas yang diberikan perlakuan pembelajaran matematika berbasis patchwork assessment lebih baik daripada kelas kontrol.

\section{DAFTAR PUSTAKA}

Brown, S., Race, P., and Smith, B. (1996). 500 Tips on Assessment. London: Kogan.

Brunsden, V. (2007a). Patchwork texts as a form of assessment. Higher Education Academy Psychology Network Newsletter, 44, 4-5.

Dewi, P. D. K. \& Suweken, G. (2014). Pengaruh Patchwork Assessment terhadap Kemampuan Koneksi Matematika pada Siswa Kelas X SMK PGRI 3 Denpasar Ditinjau dari Kompetensi Awal Siswa. Jurnal Pendidikan dan Pembelajaran Matematika Indonesia, 3(1).

Kouba, V.L. et al. (1988). Results of the Fourth NAEP Assessment of Mathematics, Arithmetic Teacher.

Leigh, J. A., Rutherford, J. M., Wild, J., Cappleman, J., \& Hynes, C. (2013). The Patchwork text assessment-an integral component of constructive alignment curriculum methodology to support healthcare leadership development. Journal Education and Training Studies, 1(1), 139-150.

Mullis, I. V. S. et al. (2016). TIMSS 2015 International Results in Mathematics. Retrieved from Boston College, TIMSS \& PIRLS International Study Center. (Online) Tersedia: http://timssandpirls.bc.edu/timss2015/international-results/

NCTM. (2000). Principles and Standards for School Mathematics. (online). Tersedia www.nctm.org

OECD. (2015). PISA 2015 Results in Focus Indonesia. (Online). Tersedia: http:// https://www.oecd.org/pisa/pisa-2015-results-in-focus.pdf.

Ovens, P. (2003). Editorial. Innovations in Education and Teaching International, 40(2), 109-112.

Raelin, J. (2000). Work-Based Learning: The New Frontier of Management Development. New Jersey: Prentice Hall.

Ruspiani. (2000). Kemampuan Siswa dalam Melakukan Koneksi Matematis. Tesis. Bandung: UPI. (tidak diterbitkan).

Sugiyono. (2010). Metode Penelitian Kuantitatif, Kualitatif \& RND. Bandung: Alfabeta.

Wesson, C. J. (2013). Introducing Patchwork Assessment to a Social Psychology Module: The Utility of Feedback. Psychology Teaching Review, 19(2), 97-105. 


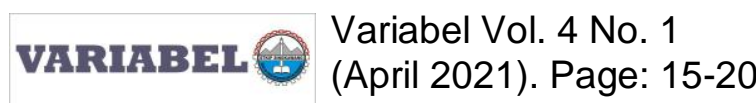

Winter, Richard., Parker, Jan., and Ovens, Peter. (2003). (Eds.): The Patchwork Text: A Radical Reassessment of Coursework Assignments. A 'Special Issue' of Innovations in Education and Teaching International, 30(2), May 2003. 